the mixture of ore and oil could be fed by means of a cock. At first this pipe was placed in a Bunsen combustion furnace but no reduction occurred as the necessary temperature could not be reached. It was then passed through a Brown assay furnace, entering through a hole cut in the back and passing out the door with the end nearer the cup being slightly elevated. The coke fire around this gave ample heat without the use of a blast. The pipe extended some inches from the furnace acting as a condenser.

Fifty grams of zinc oxide mixed with enough oil to make it pass through the cock was the usual charge. The oil required for this was in considerable excess of the amount needed for reduction. So-called "black oil," the crude with kerosene and the lighter oils removed, was used at first and later the regular crude; either will answer.

After the furnace was heated the charge was run in. An effort was made to pass it in slowly, but with this rough apparatus usually without success as almost the entire charge passed in at once. An evolution of gas from the oil on the heated surface followed. The charge remained in the heated pipe for twenty to thirty minutes when the pipe was removed and cooled and the contents examined. Beautiful specimens of zinc were found in the condensing portion of the pipe and there was an almost complete absence of "blue powder."

Some of the zinc was feathery as if both the oxide and the oil were in a volatile state when reduction occurred. This reduction in a gaseous condition greatly shortens the time required as the reducing gas is in immediate contact with the oxide to be reduced.

The gas generated by the excess of oil together with the carbon monoxide formed in the reduction was frequently lighted as it passed out of a burner connected with the end of the pipe. It should be possible to use the gases to heat the pipe or other retort containing the charge, largely reducing the fuel expense.

A number of trials were made with uniformly good results. From our experiments we conclude:

First, that zinc ores can be successfully treated, after roasting, by using crude petroleum as a reducing agent.

Second, that the theoretical advantages from the high reducing power of the oil and from the gaseous state of oxide and reducing agent, hold in a practical test.
We believe further that a continuous process based on these principles would be much cheaper, more rapid and more easily controlled than any process now in use. Arrangements have already been made for trying out the process on a large scale using the continuous process furnace devised by one of us. ${ }^{1}$

Whitcomb CHEMical LABORATORY,
DRURY COLLEGE

SPRINGFIELD, MISSOURI.

\section{TINCTURE OF IODINE.}

By Azor Thurston.

Received July 31, 1909.

Prior to the last edition of the United States Pharmacopoeia, tincture of iodine consisted simply of iodine dissolved in alcohol. Owing to the rapid loss of free iodine by the formation of either ethyl or hydrogen iodide the pharmacopoeial standard has been changed, by the addition of potassium iodide, to prevent the conversion of the free iodine into iodides.

In the assay of the tincture determinations should be made for iodine, potassium iodide, ethyl and hydrogen iodides, and alcohol.

Iodine is determined by the well-known U. S. P. method by titrating five cubic centimeters with decinormal thiosulphate solution, whereby sodium iodide and sodium tetrathionate are formed: $2 \mathrm{Na}_{2} \mathrm{~S}_{2} \mathrm{O}_{3}+\mathrm{I}_{2}=2 \mathrm{NaI}+\mathrm{Na}_{2} \mathrm{~S}_{4} \mathrm{O}_{8}$. The number of cubic centimeters decinormal sodium thiosulphate used multiplied by 0.01259 will give the amount in grams of free iodine in $5 \mathrm{cc}$. of the tincture, and by multiplying the product by 20 gives the number of grams of iodine per IOO cc.

Potassium iodide is estimated according to LaWall ${ }^{2}$ by evaporating the tincture on a water bath, adding several small successive portions of water, drop by drop, to aid in volatilizing the last portions of the iodine, and weighing the white crystalline residue in a tared watch-glass, which should be used for the experiment.

The writer prefers to determine the potassium iodide as follows: Place $5 \mathrm{cc}$. of the tincture in a platinum crucible and add 2 cc. dilute sulphuric acid; evaporate on a water bath until the alcohol and most of the free iodine are volatilized, then heat to dryness over direct flame, ignite to whiteness, cool and weigh. The residue will consist of potassium sulphate, and the weight obtained multiplied by 1.9 will equal the amount of potassium iodide

1 Hughes, Minin, World, July 10, 1909.

2 Proc. A. P. A., 1207, 159. 
present in $5 \mathrm{cc}$. of the tincture; this product multiplied by 20 will give the quantity in grams per roo cc.

Ethyl and Hydrogen Iodides.-A number of methods have been suggested to determine iodine in mixtures containing free iodine, iodides, bromides and chlorides. In nearly every case some manner of liberating the total amount of combined iodine, existing as iodides, and finally estimating the free iodine with sodium thiosulphate, has been recommended. The free iodine, having been determined in a separate portion, is deducted from the total amount of iodine, the difference being the amount of iodides present.

The majority of the methods are applicable in the assay of tincture of iodine, by first determining the free iodine and potassium iodide, as has been outlined, and then estimating the amount of total, combined and free, iodine in the tincture by one of the methods to follow; the iodine in the free state and that existing as potassium iodide is deducted from the total iodine found, and the difference is the amount existing as either ethyl or hydrogen iodide.

Richard $^{1}$ determines the amount of free iodine in ro $\mathrm{cc}$. of the tincture with sodium thiosulphate in the usual manner and then adds a two per cent. solution of potassium iodate; the coloration produced is decolorized with sodium thiosulphate solution. The difference between the thiosulphate solution necessary to decolorize the original tincture and that required to decolorize it after the addition of potassium iodate indicates the amount of hydrogen iodide present.

$\mathrm{Cook}^{2}$ proposes the addition of hydrogen peroxide to a solution of iodides acidified with acetic acid. Thus the iodine is liberated; the iodine extracted with chloroform and titrated in the usual manner.

Villiers and Fayolle ${ }^{3}$ proposed to liberate the iodine from iodide with a solution of ferric chloride, extracting the free iodine with carbon bisulphide, and treating with sodium thiosulphate.

Barrie $^{4}$ liberates the iodine with a 5 per cent. solution of potassium bichromate and a ro per cent. solution of sulphuric acid, extracts the free iodine with toluene and titrates as usual with sodium thiosulphate.

\footnotetext{
1 Proc. A. P. A., 1898, 745.

$2 \mathrm{~J}$. Soc. Chem. Ind., 1885, 611 .

3 Ibid.. 1894, 1093.

4 Ibid.. 1900, 933.
}

Kippenberger ${ }^{1}$ liberates the combined iodine by means of chromic acid and extracts the free iodine with chloroform and titrates with sodium thiosulphate solution.

Ditz and Margosches ${ }^{2}$ proposes to modify Barrie's method by using potassium iodate as the oxidizing agent with either dilute hydrochloric or sulphuric acid, $\mathrm{KIO}_{3}+5 \mathrm{KI}+6 \mathrm{HCl}=6 \mathrm{KCl}+3 \mathrm{H}_{2} \mathrm{O}+$ $3 \mathrm{I}_{2}$, and extracting the free iodine with toluene.

The method used by the writer is as follows: Five cc. of the tincture are placed in a separatory funnel together with I $_{5} \mathrm{cc}$. dilute sulphuric acid and 30 cubic centimeters decinormal potassium dichromate. Let stand about ten minutes and then add to the mixture $20 \mathrm{cc}$. carbon tetrachloride. Shake thoroughly, and when the liquids have separated draw off the carbon tetrachloride solution of iodine. Repeat the shaking out three times with successive portions of $10 \mathrm{cc}$. each of carbon tetrachloride; titrate the combined solutions of iodine with decinormal thiosulphate. From the amount of total iodine thus determined deduct the free iodine and combined iodine as potassium iodide; the difference will be the amount of iodine existing as either ethyl or hydrogen iodide.

Alcohol.-In determining the alcohol in tincture of iodine it becomes necessary to convert the iodine into a non-volatile iodide before distillation.

Alcock ${ }^{3}$ recommends the shaking of a convenient quantity of the tincture with mercury, until complete inversion of iodine, and then adding a small quantity of sodium or potassium hydroxide to prevent contamination of the distillate with traces of mercuric iodide.

Cameron ${ }^{4}$ states when the iodine is fixed with potash it of ten causes "bumping" and recommends the use of iron turnings.

Roscoe and Schorlemmer ${ }^{3}$ states when iodine is brought in contact with water and filings of iron or zinc colorless solutions of the respective iodides are formed.

Practically all the methods mentioned are unsatisfactory; in combining with the metals too much time is necessary and in most cases a small amount of volatile iodide is formed, and in using sodium or potassium hydroxide iodoform is formed.

Of the different methods investigated Alcock's proved the most satisfactory.

\footnotetext{
I Analyst, 1903, 256.

2 J. Soc. Chem. Ind., 1905, 45.

3 Proc. A. P. A., 1904, 583.

4 Analyst, 1902, 87.

5 "Treatise on Chemistry," Vol. 1, p. 157.
} 